Proceedings of the 2nd international conference Economic and Business Trends Shaping the Future $\mid 2021$

\title{
DISRUPTIVE TECHNOLOGIES FOR ACCOUNTING OF THE FUTURE
}

\author{
Atanasko Atanasovski \\ Faculty of Economics-Skopje, Ss Cyril and Methodius University \\ atanasko.atanasovski@eccf.ukim.edu.mk \\ Todor Tocev \\ Faculty of Economics-Skopje, Ss Cyril and Methodius University \\ todor.tocev@eccf.ukim.edu.mk
}

\begin{abstract}
Disruptive technologies in accounting represent a new evolutionary phase of accounting impacted by emerging technologies that are part of industrial revolution 4.0. The relevance of emerging technologies, their potential and the opportunities they offer for the accounting profession attract both academia and professionals with accelerated research efforts. Academia and scientific researchers must research and provide an appropriate theoretical basis to help practitioners better adapt and increase their awareness and trust in technology. This paper provides early quantitative research data on publication trends related to most disruptive technologies in accounting such as big data, data analytics, cloud, artificial intelligence and blockchain. We identified these five emerging technologies through literature review and elaborated in detail how they can change and advance the accounting profession. The research was conducted using bibliometric analysis to examine the level of coverage of each of the technologies in the period from 2016 to 2020 by analyzing the published articles by the Big Four accounting firms, professional accounting associations and institutions and high-ranking academic journals. The purpose of the research was to identify a potential gap in research preferences related to selected technologies between academia and development professionals and experts in the field. The findings highlight that there are no significant discrepancies or different views of academia and practitioners. It is a positive result indicating that academia and scientific researchers exploit in the same direction as practitioners, thus providing support for adaptation and alignment to technology trends.
\end{abstract}

Keywords: big data, blockchain, accounting, emerging technologies, cloud

JEL classification: $M 15, M 41, O 33$

http://hdl.handle.net/20.500.12188/15936

http://doi.org/10.47063/EBTSF.2021.0024 